\title{
A Prospect Theory Approach to Understanding Conservatism
}

Steve Clarke,

School of Humanities and Social Science,

Charles Sturt University,

April 2017

stclarke@csu.edu.au

1. Introduction

It is notoriously hard to pin down exactly what it means to describe someone as conservative (Mueller 2006, p. 359; Oakeshott 1962, p. 168). Nevertheless, there is widespread agreement about a combination of attributes that someone needs to possess if they are to be counted as a conservative. Conservatives are said to lack definite political ideals, goals or ends, to prefer the political status quo to its alternatives, and to be risk averse. In their characterization of what it is to be conservative Brennan and Hamlin (2004, pp. 676-82) make all three of these points, as does Beckstein (2015), as does O’Hara (2011, pp. 86-93).

It's not at all obvious what a lack of definite political ideals, a preference for the political status quo, and risk aversion have to do with one another. Why should these three highly distinct attributes, which are widely believed to be characteristic of adherents to a significant 
political position, cluster together? As I read them, Brennan and Hamlin (2004), Beckstein (2015) and O'Hara (2011), all take a commitment to the political status quo to be central to conservatism. ${ }^{1}$ They all offer useful contributions to the analysis of conservatism, however none of these authors fully explains why conservatives combine a preference for the status quo with a lack of definite political ideals and an aversion to risk. In particular, none appear to satisfactorily explain why a preference for the status quo should lead to an aversion to risk. $^{2}$ It is possible to prefer the political status quo to its alternatives without also being risk averse.

In this paper I will draw on prospect theory to develop an explanation for the clustering of attributes that is characteristic of conservatives. On my account, a lack of political ideals is the underlying driver of conservatism. I will provide reason to believe that people who lack political ideals are disposed to prefer the political status quo to its alternatives; as well as reason to believe that people who prefer the political status quo to its alternatives are disposed to be risk averse, at least with respect to significantly many of the risks that arise in the social and political domain. I'll also consider and reject some other potential explanations for the clustering of attributes that is characteristic of conservatives. One line of explanation which appears worth considering is that there are logical connections to be discerned between the three attributes. If we could discern logical connections between the three, then, on the assumption that ordinary conservatives are disposed to reason logically, we could explain why possession of one of the three attributes disposes conservatives to acquire the others. However, I will argue that this approach will not succeed. Another possible way to develop a suitable explanation would be to locate a fourth attribute that is plausibly attributable to conservatives, and attempt to explain why, if someone possesses such a fourth attribute that they will be disposed to acquire the other three. I will consider three potential fourth 
attributes, but argue that none of them can be used to explain why conservatives are disposed to acquire the other three attributes.

The paper will proceed as follows. In the next section, I will say more about what it is to be conservative: what it is to lack political ideals, what it is to prefer the political status quo, and what it is to be risk averse. In Section Three, I'll consider appeals to potential fourth attributes. I'll examine three possible fourth attributes that are plausibly attributable to conservatives: interests, core personality features, and status quo bias - and demonstrate that none of these provide the basis for successful explanations of the clustering of attributes that are characteristic of conservatives. I'll then consider possible logical relationships between a lack of definite political goals, a preference for the status quo and risk aversion in Section Four. I will argue that no one of the three attributes, commonly associated with conservatism, logically implies the presence of either of the others. In Sections Five and Six I will provide the conceptual apparatus needed to understand prospect theory and understand its application to the problem at hand. In Section Seven I'll present my preferred explanation for the clustering of the three attributes that are characteristic of conservatives. I'll also offer some policy advice for both conservatives and non-conservatives, which follows from my explanation.

Before I go on I need to address a terminological issue: The term 'conservative' is sometimes used very broadly to refer to anyone and everyone with right-wing political views, including libertarians. Libertarians do not count as conservatives in the sense of the term 'conservative' that is relevant here, ${ }^{3}$ because libertarians possess political ideals, and are not content with the political status quo. The ideal society libertarians aspire to create is one in which there is minimal state interference in the lives of individuals. The political status quo in every 
contemporary society is one in which there is significantly more state interference in the lives of individuals than libertarians are willing to accept, so libertarians cannot be said to be happy with the current political status quo. Use of the very broad sense of the term 'conservative' is most common in the United States. ${ }^{4}$ Sometimes American authors will use the term 'social conservative' when they wish to pick out a conservative in the more restricted sense. I intend the term 'conservative' in this more restricted sense. Modern day conservatives, in the sense of the term I am using, include Kekes (1998), O’Hara (2011) and Scruton (2014).

2. The Attributes of Conservatives

\section{(i) Lack of political ideals}

Most of the terms that we use to identify people's political positions refer to the ways in which they aspire to reform society. Libertarians aspire to create a society in which there is minimal state interference in the lives of individuals, and in which individual autonomy and freedom of choice are maximised. Communists aspire to create a society in which the means of production are collectively owned, and fascists aspire to create a society in which the interests of the nation state are paramount. The conservative is different because she lacks the aspiration to reform society. She is happy with the social institutions, values and traditions that we have now and she thinks others should be too. Non-conservatives hope for a society that accords with their ideas of what society should be like. The conservative advises us to try to see the good in what we already have.

An evocative description of conservative attitudes is due to Michael Oakeshott: 
To be conservative ... is to prefer the familiar to the unknown, to prefer the tried to the untried, fact to mystery, the actual to the possible, the limited to the unbounded, the near to the distant, the sufficient to the superabundant, the convenient to the perfect, present laughter to utopian bliss. Familiar relationships and loyalties will be preferred to the allure of more profitable attachments; to acquire and to enlarge will be less important than to keep, to cultivate and enjoy; the grief of loss will be more acute than the excitement of novelty or promise (1962, p. 169).

Conservatism is sometimes characterised in terms of an aspiration or goal: the aspiration to retain the political status quo in a given society. ${ }^{5}$ But this is potentially misleading. Genuine conservatives prefer the status quo because it is the status quo and not because it embodies any particular values. ${ }^{6}$ A North Korean who sought to retain the institutions, traditions and values that are current in North Korea, because she believed that these realise the ideals embodied in the North Korean ideology of juche, would not usually be regarded as a genuine conservative. A conservative who valued these institutions, traditions and values, would do so because these are the status quo in North Korea, and because she saw some good in them, whereas our North Korean ideologue takes the ideology of juche to describe the best possible form for a human society, and believes that contemporary North Korean society contains institutions, traditions and values that embody this form.

A genuine conservative lacks a commitment to the ideals that non-conservatives uphold. Edmund Burke, who is generally considered to be a seminal figure in the development of modern conservative thought, was a conservative par excellence. Because of his lack of commitment to political ideals he was willing to support an impressively diverse range of 
political status quos. Huntington informs us that Burke '... defended Whig institutions in England, democratic institutions in America, autocratic institutions in France, and Hindu institutions in India' (1957, p. 463). He defended these various institutions because they happened to have become the status quos in the respective places in which they took hold, but not because of his belief in any of the ideals guiding them.

The assertion that conservatives lack political ideals is sometimes broadened out to become the assertion that conservatives lack an ideology. ${ }^{7}$ Other authors, such as Huntington, suggest that conservatives can and do endorse ideologies, but these are ideologies that do not involve a 'substantive ideal' stipulating how all human societies ought to be organised (1957, p. 457). The debate about whether or not conservatives can or cannot endorse ideologies, while still remaining conservatives, boils down to a verbal dispute about whether or not a genuine ideology must involve commitment to a substantive political ideal (Beckstein 2015, p. 8). This is a dispute that we can side-step by focussing on the conservative's lack of political ideals rather than worrying about whether or not conservatives have an ideology.

(ii) A preference for the status quo

Although conservatives try to see the good in the political status quo, this does not mean that they will be able to find the good in each and every political status quo. Some status quos are unstable and do not remain the status quo for long. Other status quos do not enable many people to lead satisfying lives. Not many conservatives would support the political status quo in the superstate Oceania, described in George Orwell's dystopic novel Nineteen EightyFour, (1949) because Oceania does not appear to be a society in which many satisfying lives could be led. ${ }^{8}$ However, in most cases, according to conservatives, there is good to be found in the political status quo. Conservatives see typical human societies as having emerged 
slowly, naturally and organically, and see this as the best way for human societies to develop (Huntington 1957, p. 456). Typically, the end result of natural, incremental societal development, according to conservatives, will be social structures, traditions and values that enable many people to lead satisfying lives (Kekes 1998, pp. 48-67).

Although conservatives generally favour retaining the status quo, they are often quite willing to concede that there are possible circumstances which would be superior to the status quo, and which would be worth aspiring to create, if only this were feasible. ${ }^{9}$ A non-conservative in Australia might point out to a conservative that $13.3 \%$ of Australians currently live below the OECD poverty line, and that Australia would be a better society if nobody lived below the OECD poverty line. Most conservatives would agree that Australia would be a better society if nobody lived below the OECD poverty line, but are likely to baulk at proposals to engineer a poverty-free Australian society. A persistent theme in conservative political philosophy is the propensity of schemes to reform society to fail and to result in unintended states of affairs that are inferior to the status quo - which is to say that such schemes tend to backfire (Buchanan 2011, p. 146). Conservatives stress that societies are exceedingly complex and that our understanding of their complexities is minimal (O'Hara 2011, pp. 525). Current and previous attempts to overhaul social structures, such as the various attempts to create ideal socialist societies in Twentieth Century communist states, seem to have been based on an inadequate understanding of the complexities of social structures. So, it is not surprising, say conservatives, that many of these attempts went horribly wrong.

Conservatives are opposed to grand social engineering projects, but are not usually opposed to incremental departures from the status quo, aimed at enabling more people to lead satisfying lives, and at enabling people who are currently leading satisfying lives to lead even 
more satisfying lives (e.g. Oakeshott 1962, pp. 170-2; Scruton 2002, p. 11). Conservatives usually also accept that there are times when social institutions, traditions and values need to be reformed to enable them to adapt to changing circumstances (e.g. O'Hara 2011, pp. 88-9). Social structures will sometimes need to be reformed to deal with changes to the environments that human societies are located in. For example, in the aftermath of a devastating earthquake, the welfare distributing institutions a society has established may be unable to provide proper care for all those who need it, traditions regarding the treatment of the poor may be compromised, and values relating to care for the poor may not be fully upheld. In the face of such challenges the conservative will be concerned that established institutions, traditions and values continue to exist, even if they are no longer quite the same institutions, traditions and values as they were before. The conservative is disposed to accepting compromise and reform, when necessary, rather than risk social breakdown.

(iii) Risk Aversion

To be risk averse is to prefer to take smaller than greater risks, and be willing to forego the possibility of significant gain in order to minimise the risk of loss. To prefer a certain gain of $\$ 1$ to a 1 in 10 chance of receiving $\$ 10$ is to be risk averse. To prefer a 1 in 10 chance of receiving \$10 to a certain gain of \$1 is to be risk seeking. Someone who is strongly risk averse will be willing to accept inferior expected utilities in order to avoid risks. They may prefer a certain payment of $\$ 1$ to a 1 in 10 chance of receiving $\$ 20$, even when they are aware that the expected utility of a 1 in 10 chance of receiving $\$ 20$ is twice as much as the utility of a certain gain of $\$ 1$. Similarly, someone who is strongly risk seeking may prefer a 1 in 10 chance of receiving $\$ 5$ to a certain payment of $\$ 1$, even when they are aware that the expected utility of a 1 in 10 chance of receiving $\$ 5$ is half as much as $\$ 1$. 
Some non-conservatives might be at least somewhat risk averse and the various commentators who describe conservatives as risk averse do not appear to deny this possibility. By singling out conservatives as risk averse these commentators imply that, on average, conservatives are significantly more risk averse than non-conservatives. ${ }^{10}$ Do those who describe conservatives as risk averse mean to suggest that they are risk averse in each and every context or do they just mean to suggest that conservatives are risk averse in the political domain? None of the three cited authors, who describe conservatives as risk averse, address this issue. Available evidence is mixed. Dohmen at al. provide evidence for the conclusion that attitudes to risk are 'relatively stable across different contexts' (2011, p. 542). However, Choma et al. (2014) found evidence of cross-contextual variance in attitudes to risk. Choma et al's. (2014) results are especially relevant to us because they provide specific evidence of cross-contextual variance in conservatives' attitude to risk. According to them, conservatives are less willing than liberals to take risks in the social and political domain, but more willing to 'engage in risky financial activities than are liberals' (Choma et al., 2014, p. 718). Given the lack of clarity in the literature about the degree to which risk aversion is subject to cross-contextual variance, the most charitable interpretation of Brennan and Hamlin (2004), O'Hara (2011) and Beckstein (2015), is that these authors are only committed to the claim that conservatives are risk averse when considering risks that arise in the social and political domain.

A further qualification we need to make, to the claim that conservatives are risk averse, is that the authors who make this claim are most charitably interpreted as only intending to assert that conservatives are risk averse when contemplating the risks associated with the implementation of plans directed at making potential gains in the social and political domain. Many conservatives appear to display risk-seeking behaviour when contemplating threats to 
established institutions in the social and political domain. Conservatives appear to be no less willing, than non-conservatives, to accept the risks involved in going to war, to defend the established social and political institutions that they value, for example.

A fairly extreme recent example of risk-seeking conservative behaviour, in response to a perceived threat to established social and political institutions, can currently be observed amongst contemporary populist conservative politicians in Australia, who are very concerned about fundamentalist Muslim proposals to introduce Sharia law into Australia, something which they see as incompatible with established Australian legal institutions and procedures. Some of these politicians, such as Senator Jacqui Lambie, seem willing to impose significant political risks on Australia to head off this perceived threat, even though the prospect of Australia, with only a tiny Muslim population (approximately 2\%), adopting Sharia law and abandoning its current legal system, seems remote. For example, Lambie has suggested that advocates of Sharia law should be denied the right to vote in Australian elections (Owens 2014). The principle of universal suffrage is a cornerstone of the democratic tradition in Australia (and elsewhere) and proposing that it be compromised in cases where particular controversial views are propounded would set a very dangerous precedent, so this seems to be a clear instance of conservative risk-seeking behaviour.

3. Possible Fourth Attributes

\section{(i) Interests}

A traditional way of trying to explain why conservatives are conservative is by appealing to their self interest, or class interest (Mueller 2006, p. 361; Beckstein 2015, pp. 9-10; Sears and 
Funk 1991). This approach looks like it could account for at least two of the three attributes of conservatives that we would like to account for. Conservatives value the political status quo because it is in their interest to retain the political status quo, which they benefit from, and they lack political ideals because it is not in their interest to adopt political ideals. Adopting political ideals would, almost always, involve them advocating a departure from the political status quo and this is not in their interest. However, it is not clear how an appeal to interests could be used to explain the conservative tendency to be risk averse.

A further weakness of this approach to explaining why people are conservative is that it can only be applied to those conservatives who actually benefit from the political status quo. Many conservatives plainly do not benefit from the political status quo. As is often observed, conservative-dominated American 'Red States' are significantly poorer, on average, than liberal American 'Blue States'. ${ }^{11} 97$ of the 100 poorest counties in America are to be found in Red States. ${ }^{12}$ The political status quo in America does not benefit the residents of conservative Red States nearly as much as it benefits the residents of liberal Blue States. So, it is hard to see how appealing to either self-interest or class-interest can explain why many conservatives are conservative.

\section{(ii) Personalities}

Another suggestion is that people tend to adopt particular political outlooks because of core features of their personalities. The appeal to core personality features to explain the popularity of political outlooks was very influential in the mid-Twentieth Century. The best known exemplar of this appeal is Adorno et al.'s (1950) 'The Authoritarian Personality', which sought to associate a disposition to adopt a conservative political outlook with the 
personality traits of respecting authority and hierarchy (which was, in turn, given a Freudian explanation). ${ }^{13}$

Not surprisingly, work associating personality traits with political outlook has been tarnished by the suspicion of political bias (Ray 1988; Tetlock 1994). It has also been countered by studies which suggest that political orientation is 'consistently and strikingly unrelated to personality and temperament factors' (Mehrabian 1996, p. 469). Some recent studies, including Carney et al. (2008), do suggest that there are personality differences between liberals and conservatives. Carney et al. (2008) found evidence that conservatives are more 'conventional, orderly, organized, neat, clean, withdrawn, reserved and rigid' than liberals (2008, p. 834). But these differences do not seem to explain why conservatives lack political ideals, prefer the political status quo and are risk averse. If anything, it would seem that a rigid, organised person should prefer a well-organised ideal state to the chaos of the current political status quo. It is unclear whether or not the character traits that Carney et al. (2008) associate with conservatives gives us reason to think that conservatives will be risk averse. ${ }^{14}$

\section{(iii)Status quo bias}

Another possible ground for explaining the conjunction of risk aversion, a preference for the status quo, and a lack of political ideals, which characterises conservatives, is work in cognitive science on 'status quo bias'. According to cognitive scientists, we have a persistent bias in favour of status quo options. There are two principal components of status quo bias: the 'endowment effect' and 'loss aversion' (Kahneman et al., 1991). ${ }^{15}$ The endowment effect causes people to ascribe extra value to items which they regard as possessions. So the endowment effect causes people to value the status quo more highly than they would otherwise, at least with respect to items that they regard as owned; and it thereby contributes 
to status quo bias. Loss aversion is a pervasive and well established psychological phenomenon. We feel the pain of losses more than we feel the benefits of gains (Kahenman 2011, pp. 283-4). Because we feel the pain of losses more than we feel the benefits of gains we tend to not to act on opportunities to improve our circumstances, unless these are markedly in our favour. Because loss aversion leads us to forego many opportunities that are only marginally in our favour it contributes to status quo bias.

An appeal to status quo bias can be used to explain the conservative's preference for the status quo, and the endowment effect and loss aversion looks like candidates to play a central role in an explanation of risk aversion. The additional value that we ascribe to items we are endowed with appears to help explain why we are often unwilling to take risks that involve a chance of loss of items we possess, even when taking such risks is in our interests, all things considered. Similarly, our persistent aversion to losses looks like it will explain why we are unwilling to take risks which involve a chance of losses that it might be in our interest to take.

It seems that we might be able to account for at least two of the three attributes of conservatives that we would like to be able to account for by appealing to status quo bias. Unfortunately, this appearance is misleading. What we need to account for is a combination of attributes that is peculiar to conservatives. But status quo bias is a universal phenomenon. We cannot explain why conservatives prefer the political status quo more than do nonconservatives, merely by appealing to status quo bias, because everyone is subject to status quo bias (Kahneman et al. 1991; Kahenaman 2011). Similarly, we cannot explain why conservatives are more risk averse than non-conservatives merely by appealing to status quo bias, because everyone is subject to status quo bias (Kahneman 2011). What we need is an 
explanation that enables us to understand why conservatives prefer the political status quo more than do non-conservatives, are more risk averse than non-conservatives, and lack the political ideals that non-conservatives have. I will go on to show how such as explanation can be provided by appealing to prospect theory. This is a theory that subsumes earlier findings due to cognitive scientists regarding status quo bias (Kahneman 2011). I will say more about prospect theory in Sections Five and Six. First though, I will consider possible logical connections between a lack of political ideals, a preference for the political status quo, and risk aversion.

\section{A Lack of Logical Connections}

Suppose I have no political ideals. Does it follow that I will prefer the political status quo to available political alternatives? No it does not. In the absence of a reason or motive to prefer the status quo to available alternatives I will be indifferent between the status quo and available alternatives. Does it follow that I will be risk averse? Again the answer is no. If I am indifferent between options then, in the absence of other considerations, ${ }^{16}$ I will also be indifferent between accepting one of these options and sticking to it, and switching between options. But, if I am risk averse then my preference will be to stick to one option, and thereby avoid taking the risks involved in switching between options.

Suppose now that I prefer the status quo to available political alternatives. Does it follow that I will lack political ideals? No it does not. As we saw earlier, it is possible to prefer the status quo and have political ideals. This will happen when one takes the status quo to be a state in which one's political ideals are realised. Does it follow that I must be risk averse? No it does 
not. It follows that I will not want to risk altering the political status quo, which I prefer, for a chance at realising a political ideal which I do not prefer. But I can be justified in avoiding such risks regardless of whether or not I am risk averse. It is never worthwhile taking such risks, from my point of view, regardless of whether I am risk averse or not, because the payoff of taking such risks is always going to be negative.

Suppose I am risk averse. Does it follow that I will lack political ideals? No. It is logically possible for me to aspire to change society so that it matches my political ideals but also to insist on minimising the risks involved in making such changes. Does it follow that I will prefer the status quo to available political alternatives? No it does not. I might prefer a particular conception of an ideal society to the status quo, but take a risk-averse attitude to the risks involved in altering the political status quo and enabling the realisation of my political ideals. In summary, there are no logical connections between a lack of political ideals, a preference for the political status quo and risk aversion.

\section{Prospect Theory}

Psychological studies of people's behaviour in situations involving risk suggest that most people are strongly risk averse in some circumstances and strongly risk seeking in others (Kahneman 2011). The best available descriptive theory of ordinary behaviour in situations of risk is Kahneman and Tversky's (1979) hugely influential prospect theory, which I will now introduce. ${ }^{17}$ I'll start by working through Tversky and Kahneman's (1981) famous 'Asian disease problem'. 
Tversky and Kahneman (1981) asked 152 research subjects to read the following passage and indicate a preference between two programs described in it:

Imagine that the U.S. is preparing for the outbreak of an unusual Asian disease, which is expected to kill 600 people. Two alternative programs to combat the disease have been proposed. Assume that the exact scientific estimates of the consequences of the programs are as follows:

If Program A is adopted, 200 people will be saved.

If Program B is adopted there is a one-third probability that 600 people will be saved and a two-thirds probability that no people will be saved.

Which of the two programs would you favour? (1981, p. 453).

The two outcomes have the same expected utility. However, Program A leads to a certain outcome, whereas the outcome of Program B is uncertain. Program A was preferred by $72 \%$ of Tversky and Kahneman's (1981) research subjects, while Program B was preferred by only $28 \%$. So, $72 \%$ of their subjects appeared to be risk averse, and $28 \%$ appeared to be risk seeking. 155 subjects were then asked to consider a variation on the scenario described in the first passage. In this variation subjects were asked to indicate a preference for either Program C or Program D:

If Program C is adopted, 400 people will die.

If Program D is adopted, there is a one-third probability that nobody will die and a two-thirds probability that 600 people will die. 
Which of the two programs would you favour? (1981, p. 453).

Program C and Program D have the same expected utility. However, Program C leads to a certain outcome, whereas the outcome of Program D is uncertain. Program C should appeal to the risk averse and Program D to the risk seeking, so if risk aversion and risk seeking attitudes were consistent across different situations we would expect about $72 \%$ of subjects to prefer Program C and about $28 \%$ to prefer Program D. However, only $22 \%$ of Tversky and Kahneman's (1981) subjects preferred Program C, while 78\% preferred Program D. It seems that the attitude of the majority of people towards risk is subject to dramatic shifts. When asked to choose between Program A and Program B the clear majority of subjects displayed risk-averse preferences. When asked to choose between Program C and Program D the clear majority displayed risk-seeking preferences. What is particularly striking about these results is that the situation of choice between Program A and Program B and the situation of choice between Program C and Program D are not genuinely different. What is different is the way that they are presented (or 'framed'). The choice between Program A and Program B is framed as a situation of deciding whether or not to accept risk when lives can be saved, whereas the choice between Program C and Program D is framed as a situation of deciding whether or not to accept risk when lives stand to be lost. A is C, but framed in terms of lives saved rather than lives lost; and B is D, framed in terms of lives saved rather than lives lost.

The results of the Asian disease problem, as well as a slew of other experimental findings, can be accounted for by appealing to prospect theory (Kahneman 2011; Kahneman and Tversky 1979; Tversky and Kahneman 1992). 
Prospect theory involves three central claims. ${ }^{18}$

1. We evaluate risks by comparing them to neutral reference point. ${ }^{19}$ Outcomes that are understood as being superior to this reference point are experienced as gains.

Outcomes that are understood as being inferior to this reference point are experienced as losses.

2. We are loss averse. Losses have more of a psychological impact on us than gains. Most of us can empathise with the sentiments of the tennis player Jimmy Connors, who famously declared, 'I hate to lose more than I love to win'.

3. We experience diminishing sensitivity to gains and losses as these depart from our reference point. If our reference point is $\$ 0$ then the first $\$ 100$ we stand to gain will have more psychological significance for us than the next $\$ 100$ we stand to gain, which will itself have more psychological significance that the next $\$ 100$ we stand to gain, and so on. Mutatis mutandis for losses.

These three principles taken together give us the outcomes illustrated in the below diagram: ${ }^{20}$ 


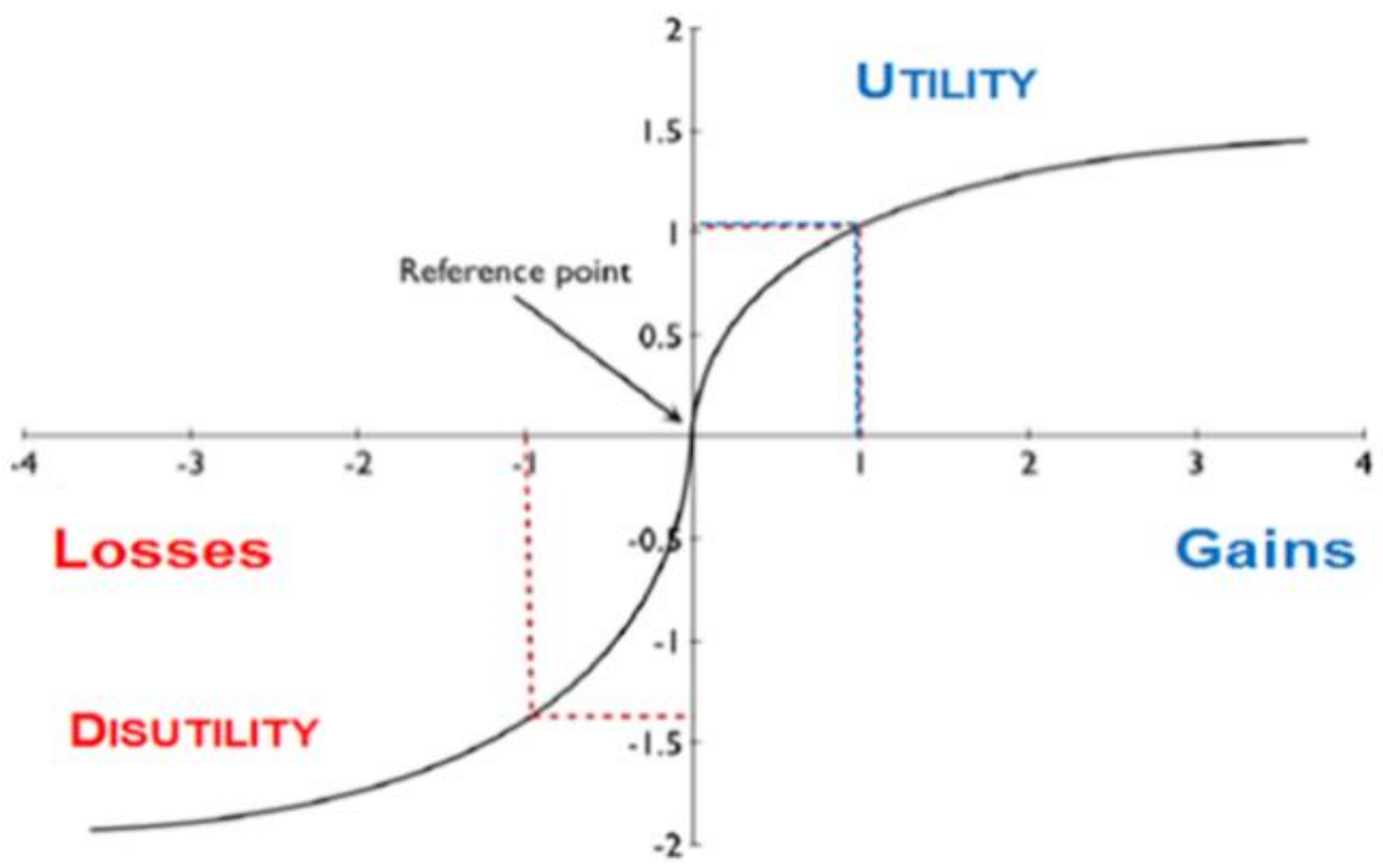

Loss Aversion Ratio $=1.4$

According to prospect theory, the ways in which available choices are framed can have a major influence on the location of our reference point; the location of our reference point determines which outcomes we experience as gains and which outcomes we experience as losses; and the experience of outcomes as either gains or losses determines whether we are risk averse or risk seeking. We tend to be risk averse when choosing between potential gains above a reference point; and so it makes sense that the clear majority of Tversky and Kahneman's (1981) subjects would choose Program A over Program B. We tend to be risk seeking when choosing between potential losses relative to a reference point, so it makes 
sense that the clear majority of Tversky and Kahneman's (1981) subjects would take the risky bet, and choose Program D, which provides a chance of avoiding loss altogether.

As well as choices between gains and choices between losses, there are 'mixed options', in which we risk suffering losses and have the opportunity to make gains. According to prospect theory losses have a greater psychological impact on us than equivalent gains; and so people are generally loss averse when facing mixed options. As prospect theory predicts, most people exhibit risk-averse preferences when faced with mixed options. If offered a bet which involves a 50\% chance of losing $\$ 100$ and a 50\% chance of gaining $\$ 150$ most people decline the bet (Kahneman 2011, p. 283), even though the expected utility of accepting it is $+\$ 25$. Most people's 'loss aversion ratio' is somewhere between 1.5 and 2.5 (Kahneman 2011, p. 284). In the diagram above, a loss aversion ration of approximately 1.4 is depicted. Someone with a loss aversion ratio of 1.4 would need to be offered a $50 \%$ chance of winning $\$ 140$ or more to induce them to accept a bet that involved a $50 \%$ chance of losing $\$ 100$. To them, the psychological pain of losing $\$ 100$ outweighs the psychological benefit of winning any amount below $\$ 140$.

6. Goals as Reference Points

Finding the reference point that people use to differentiate gains from losses is crucial for understanding their attitudes to risk. The psychology behind the location of reference points is not fully understood (van Osch et al. 2006, p. 338). It seems, though, that reference points are often implicitly given by the way in which we understand the situations we are in. In 
many circumstances the status quo is our default reference point; which is why prospect theory can account for evidence of status quo bias. In circumstances where risks to possessions arise it provides a clear explanation of a key contributor to status quo bias: the endowment effect. In contexts in which we are considering possessions, our reference point will usually be what we are currently endowed with. When we own one property our reference point will usually be one property. We will be risk averse when contemplating the purchase of a second property, but risk seeking in responding to threats to our ongoing possession of the property we own. ${ }^{21}$

As we saw in the previous section, in the discussion of the Asian disease problem, reference points can be induced to shift by the use of subtle variations of language that can lead us to change how we construe a situation. There are also various other factors that are able to influence where reference point are set, such as expectations (Köszegi and Rabin 2006). ${ }^{22}$ If I own one property and a relative dies and bequeaths another property to me in her will, but I do not yet own it, my reference point, with regard to property ownership, is likely to shift to two properties, provided that I am sufficiently confident that the second property is going to come into my possession.

Another factor that can influence the location of reference points is having specific goals (Heath et al. 1999; Pope and Schweitzer 2011; van Osch et al. 2006). When people set specific goals for themselves, or accept ones that others set for them, these often serve as implicit reference points. When this happens, and they go on to exceed their goals, they think of the extent to which they exceed those goals as gains; and when they fail to reach their goals they think of the extent to which they fail to reach those goals as losses. Heath et al. 
(1999) provide evidence that people tend to act in a risk-seeking manner when pursing goals. ${ }^{23}$ They asked their research subjects to consider two versions of the following problem: You are the manager of a large manufacturing unit in a Fortune 100 company. At the present time, you are in the midst of a year-long plan to cut costs in your unit. [Version 1:] Your goal for this quarter is to do your best to save money during the current quarter. [Version 2] Your goal for this quarter is to save $\$ 250,000$.

At present you are considering two plans:

Plan M. Plan M will save $\$ 120,000$.

Plan N. Plan N has an $80 \%$ chance of saving $\$ 50,000$ and a $20 \%$ chance of saving $\$ 250,000$.

Both plans are one-time options. They will not be available later in the year, and you have time to complete only one of them during the current quarter.

What plan will you choose? (1999, p. 94)

When research subjects were asked to choose under the 'do your best' condition (Version 1) only $24 \%$ chose the risky, but potentially highly rewarding Plan N, rather than the risk-free Plan M. However, when subjects were asked to choose under the condition of having a specific goal (Version 2), $47 \%$ indicated a preference for Plan N. ${ }^{24}$ This result suggests that people are significantly more likely to adopt a risk-seeking, rather than a risk-averse strategy, when they have a clear goal to pursue, a finding that is consistent with the hypothesis that goals often serve as reference points. 
There is also evidence that people start to behave in a risk-averse manner once they have exceeded their goals, which is what we would expect if goals serve as reference points. Professional golfers tend to judge their play on a given hole according to whether they have made a score of par or not. A bogey (one over par) is regarded as a loss, and a birdie (one under par) is regarded as a gain. It looks like they treat a score of par as a reference point. In an incredibly detailed study Pope and Schweitzer (2011) examined 2.5 million putts using precise laser measurements. They found that even the best golfers, who are good enough to participate in PGA tour events, are significantly less accurate when putting for below-par scores, than when they are putting for par, or for an above-par score. ${ }^{25}$ This loss of accuracy seems to be evidence of risk aversion once a goal has been reached. It seems that golfers tend to hit birdie putts less hard than par putts and are more likely to leave birdie putts short of the hole than par putts. According to Pope and Schweitzer this is because they are less willing to risk having to make a difficult second putt, as a result of overshooting the hole, by hitting it too hard, when they are putting for birdie, than when they are putting for par. So, they end up leaving the ball short of the hole more often when they are putting for birdie than when they are putting for par $\left(2011\right.$, p. 131). ${ }^{26}$

\section{Understanding Conservatism}

Non-conservatives aspire to reform their society, and to keep reforming it until it closely resembles their favoured ideal. In other words, they are guided by a goal: the goal of transforming their current society into one that closely resembles their favoured ideal. Plausibly, the goals of many non-conservatives serve as reference points for them, when they 
are contemplating social and political changes. If this is right, then these non-conservatives will consider all political transformations that fall short of creating their favoured ideal as losses. They will tend to be risk seeking when pursuing social policies that advance them closer to their goals and also risk seeking in resisting the introduction of social policies that prevent their goals being attained. Non-conservatives would become risk averse if their goals were achieved and they were contemplating the possibility of exceeding those goals. But given that the ambition of most non-conservatives is to transform their current society into an ideal society, and given that most contemporary non-conservatives suppose that their current society is very far from ideal, they are unlikely to ever find themselves in political circumstances where they would become risk averse.

In the absence of a factor that can set reference points, such as a goal, our default reference point is usually the status quo. Conservatives appear to lack a reference-point setting factor, so it is reasonable to assume that their reference point, when evaluating social and political policies, is the political status quo. The fact that conservatives try to see the good in the political status quo makes it especially likely that they will treat the political status quo as a reference point. How conservatives react to proposals to depart from the status quo will depend on whether they see these as involving potential gains or losses. As has already been mentioned, conservatives accept that many of the substantive policy proposals that nonconservatives put forward would lead to social gains, if they could be successfully implemented. Their chief objection to such policy proposals is that attempts to implement them are risky and liable to lead to losses rather than gains. Because conservatives regard such proposals as proposals to make gains above their reference point, they will tend to respond to them in a risk-averse manner. They will not construe all non-conservative policy proposals as proposals to make gains, however. Proposals that involve dismantling, rather 
than building on, established social and political institutions, are likely to be understood by conservatives as proposals that would lead to losses if they were successfully implemented, and conservatives are likely to respond to these in a risk-seeking manner.

If the above reasoning is sound, then we can explain why people who lack political ideals can rightly be said to be disposed to prefer the political status quo to its available alternatives. When someone lacks political ideals their reference point will typically default to the political status quo. They will favour the political status quo over circumstances that they regard as losses from the political status quo and adopt a risk averse attitude to circumstances that they regard as gains above the status quo. So, conservatives are rightly described as having a preference for the political status quo. We can also explain why conservatives are rightly described as being risk averse. Because the reference point for conservatives is typically the political status quo, they will be risk averse in responding to policy proposals to improve upon the social and political status quo. Their behaviour stands in clear contrast with that of non-conservatives, whose reference point is at a different location, and who will tend to be risk seeking when responding to policy proposals to improve upon the social and political status quo.

As was noted in Section 1, several significant contemporary accounts of conservatism, including those due to Brennan and Hamlin (2004), Beckstein (2015) and O’Hara (2011), take a commitment to the political status quo to be central to conservatism. My explanation of the clustering of attributes that are characteristic of conservatism is both helpful to these accounts and presents a challenge to them. By explaining how a preference for the political status quo disposes one to be risk averse in the social and political domain, I offer assistance to those who take a commitment to the political status quo to be central to conservatism, and 
who would like to explain why conservatives are risk averse. However, by accounting for the conservative preference for the political status quo by appealing to the conservative's lack of political ideals, I offer a challenge to these accounts. If I am right, then there is an underlying reason for the conservative's preference for the political status quo that is not readily apparent, but which can be bought to light be the application of prospect theory. What really drives conservatism is not a preference for the political status quo but the absence of political ideals.

Now that we have explained why people who lack political ideals, prefer the political status quo to alternatives, and are risk averse - why they are conservative - we are in a position to offer policy advice to non-conservatives who want to recruit conservatives to their favoured political viewpoint. Trying to get conservatives to see what is wrong with the political status quo, or trying to get them to adopt different attitudes to risk is very unlikely to work. Because both the preference that conservatives have for the political status quo, and their attitude to risks in the social and the political domain, are driven by their lack of political ideals, nonconservatives need to convince them to adopt a particular set of political ideals before they can hope to be able to lead them to shed the other two attributes of conservatism. If political ideals are adopted, then changes in attitudes to the political status quo and to risks in the social and political domain can be expected to follow.

We are also in a position to offer political advice to conservatives who are interested in trying to recruit non-conservatives. Because their attitudes to the political status quo, and to risks in the social and political domain, are driven by their political ideals, attempts to get nonconservatives to change their attitude to the political status quo, or their attitude to risks that arise in the social and political domain are very unlikely to succeed. However, if the 
conservative can persuade non-conservatives to abandon their political ideals, and not replace these by another set of political ideals, then non-conservatives can reasonably be expected to default to the states that are characteristic of conservatism. They can be expected to acquire a preference for the political status quo over alternatives and to become risk averse when assessing risks in the social and political domain; which is to say that they can be expected to become conservatives.

\section{$\underline{\text { References }}$}

Adorno, T. W, Frenkel-Brunswick, E., Levinson, D. J. and Sanford, R. N. (1950). The Authoritarian Personality. New York: Harper.

Beckstein, Martin. (2015). 'What Does It Take to be a True Conservative?', Global Discourse 5: 4-21.

Brennan, Geoffrey and Hamlin, Alan. (2004). 'Analytic Conservatism', British Journal of Political Science, 34: 675-691.

Briggle, Adam. (2014). 'Bioconservatism as Customised Science', in The Customization of Science: The Impact of Political and Religious Worldview on Contemporary Science, edited by S. Fuller, M. Stenmark and U. Zackariasson, Basingstoke: Palgrave Macmillan, pp. 176-192.

Buchanan, Allen. (2011). Beyond Humanity? The Ethics of Biomedical Enhancement. Oxford: Oxford University Press.

Carney, D. R., Jost, J. T., Gosling, S. D. and Potter, J. (2008). 'The Secret Lives of Liberals and Conservatives: Personality Profiles, Interaction Styles, and the Things They Leave Behind', Political Psychology, 29 (6), 807-840. 
Choma, B. L. Hanoch, Y. Hodson, G. and Gummerum, M. (2014). 'Risk Propensity Among Liberals and Conservatives: The Effect of Risk Perception, Expected Benefits and Risk Domain', Social Psychological and Personality Science, 5: 713-721.

Clarke, Steve. (2009). 'New Technologies, Common Sense and the Paradoxical Precautionary Principle', in Evaluating New Technologies: Methodological Problems for the Ethical Assessment of Technological Developments, edited by Paul Sollie and Marcus Duwell, Dordrecht: Springer, pp. 159-173.

Dohmen, T., Falk, A., Huffman, D., Sunde, U., Schupp, J. and Wagner, G. G. (2011). 'Individual Risk Attitudes: Measurement, Determinants, and Behavioral Consequences', Journal of the European Economic Association, 9 (3): 522-550.

Eidelman, Scott and Crandall, Christian S. (2012). 'Bias in Favour of the Status Quo', Social and Personality Psychology Compass 6 (3): 270-81.

Handlin, O. (1963). The American People, Hamondsworth: Penguin.

Heath, C., Larick, R. and Wu, G. (1999). 'Goal as Reference Points', Cognitive Psychology, 38: 79-109.

Huntington, Samuel. (1957). 'Conservatism as an Ideology', in American Political Science Review, 51: 454-73.

Jost, J. T, Napier, J. L., Thorisdottir, H, Gosling, S. D., Palfai, T. P., and Ostafin, B. (2007). 'Are Needs to Manage Uncertainty and Threat Associated with Political Conservatism or Ideological Extremity?', Personality and Social Psychology Bulletin, 33: 989-1007. Kahneman, Daniel. (2011). Thinking, Fast and Slow. New York: Farrar, Strauss and Giroux. Kahneman, D., Knetsch, J.L and Thaler, R.H. (1991) 'Anomalies: The Endowment Effect, Loss Aversion and Status Quo Bias', Journal of Economic Perspectives, 5, 1, 193 206. 
Kahneman, D. and Tversky, A. (1979). 'Prospect theory: An analysis of decision under risk', Econometrica, XLVII: 263-291.

Kekes, John. (1998). A Case for Conservatism. Ithaca: Cornell University Press.

Kiley, Jocelyn (2014). In Search of Libertarians. Pew Research Center. Avaiable at: http://www.pewresearch.org/fact-tank/2014/08/25/in-search-of-libertarians/ . Accessed 19 October 2016.

Kirk, Russell. (1953) [2008]. The Conservative Mind. New York: BN Publishing. Köszegi, Botond and Rabin, Matthew. (2006). 'A Model of Reference-Dependent Preferences', Quarterly Journal of Economics, 121: 1133-65.

Levy, Jack S. (2003). 'Applications of Prospect Theory to Political Science', Synthese 135: $215-241$.

Martin, J. L. (2001). 'The Authoritarian Personality, 50 years later: What Lessons are there for Personality Psychology?', Political Psychology, 22, 1-26.

Mehrabian, A. (1996). 'Relations among Political Attitudes, Personality and Psychopathology Assessed with New Measures of Libertarianism and Conservatism', Basic and Applied Social Psychology, 18, 469-491.

Mueller, Jan-Werner (2006). 'Comprehending Conservatism: A New Framework for Analysis', Journal of Political Ideologies, 11: 3, 359-365

Oakeshott, Michael. (1962). 'On Being Conservative', in Rationalism in Politics and Other Essays, New York: Basic Books, pp. 168-196.

O’Hara, K. (2011). Conservatism, London: Reaktion.

Orwell, George. (1949). Nineteen Eighty-Four, London: Secker and Warburg.

Owens, Jared. (2014). 'Advocates of Sharia law should leave, or lose voting and welfare rights: Jacqui Lambie', The Australian, 15 September. Available at: http://www.theaustralian.com.au/national-affairs/advocates-of-sharia-law-should- 
leave-or-lose-voting-and-welfare-rights-jacqui-lambie/story-fn59niix1227059026256. Accessed 16 September 2016.

Pope, Devin G. and Schweitzer, Maurice E. (2011). 'Is Tiger Woods Loss Averse? Persistent Bias in the Face of Experience, Competition and High Stakes', American Economic Review, 101: 129-157.

Ray, J. J. (1988). ‘Cognitive Style as a Predictor of Authoritarianism, Conservatism and Racism, a Fantasy in Many Movements', Political Psychology 9, 303-308.

Sandin, Per. (2007). 'Common-Sense Precaution and Varieties of the Precautionary Principle', in T. Lewens (ed.) Risk: Philosophical Perspectives, London: Routledge, pp. 99-112.

Scruton, Roger (2002). The Meaning of Conservatism, $3^{\text {rd }}$ Edition. South Bend: Saint Augustine's Press.

Scruton, Roger. (2014). How to be a Conservative. London: Bloomsbury Continuum.

Sears, D. O. And Funk, C. L. (1991). 'The Role of Self-interest in Social and Political Attitudes'. Advances in Experimental Social Psychology, 24, 1-85.

Tetlock, P. E. (1994). 'Political Psychology or Politicised Psychology: Is the Road to Scientific Hell Paved with Good Moral Intentions?' Political Psychology, 15, 509529.

Turner, Stephen P. (2010). 'The Conservative Disposition and the Precautionary Principle', in The Meaning of Michael Oakeshott's Conservatism, edited by C. Abel, Exeter: Imprint Academic, pp. 204-217.

Tversky, A. and Kahneman, D. (1981). 'The Framing of Decisions and the Psychology of Choice', Science, 211: 453-58.

Tversky, A. and Kahneman, D. (1992). 'Advances in Prospect Theory: Cumulative Representation of Uncertainty', Journal of Risk and Uncertainty, 5: 297-323. 
Van Osch, S. M. C., van den Hout, W. B. and Stiggelbout, A. M. (2006). 'Exploring the Reference Point in Prospect Theory: Gambles for Length of Life', Medical Decision Making, 26: 338-46.

Viereck, Peter. (2009). Conservatism Revisited: The Revolt Against Ideology. New Brunswick: Transaction ( $3^{\text {rd }}$ Printing $)$.

Notes

${ }^{1}$ According to Brennan and Hamlin, conservatism '... is a disposition that grants the status quo a normative authority by virtue of its being the status quo' (2004, p. 676). According to Beckstein, the truly conservative '... attach a value to the status quo because it is the status quo' $(2015$, p. 18$)$. O'Hara depicts conservatism as involving a recognition that 'the current state of society is typically undervalued' (2011, p. 88).

${ }^{2} \mathrm{O}^{\prime} \mathrm{Hara}$ offers what appears to be a deductive argument, from the premises that 'the current state of society is typically undervalued and [because] the effects of social innovations cannot be fully known in advance', to the conclusion that societies should be risk averse $(2011, \mathrm{p} .88)$. The argument is not valid. It may perhaps be intended as an inference to the best explanation which been not been fully fleshed out.

${ }^{3}$ Mueller concurs. According to him, 'Libertarianism is not, by any stretch of the imagination, a form of conservatism'. He depicts libertarianism as 'part of a broad conservative coalition, especially in the United States', rather than a form of conservatism (2005, p. 364).

\footnotetext{
${ }^{4}$ The difference between American and non-American uses of the term 'conservative' has given rise to some potentially confusing commentary. Some commentators, such as Handlin $(1962$, p. 446) have denied that there are any true conservatives in America. Others, such as Kirk (1953), have
} 
argued that America ought to change in various ways, to allow a genuinely conservative political movement to develop.

${ }^{5}$ E. G. Huntington (1957, p. 455).

${ }^{6}$ Beckstein argues similarly (2015, p. 12).

${ }^{7}$ E. G. Viereck (2009, pp. 153-4).

${ }^{8}$ In a similar vein, Kekes suggests that conservatives should regard a status quo that involves slavery as unacceptable $(1998$, p. 40)

${ }^{9}$ According to O'Hara conservatives should concede that they do not know that any given social reform will be unsuccessful, and should welcome social reforms that have been implemented, when it becomes clear that the benefits of these have outweighed costs (2011, pp. 56-7).

${ }^{10}$ A suggestion I will not pursue here is one due to Turner (2010) and Briggle (2014). Both authors suggest that conservative attitudes to risk are embodied in the 'precautionary principle'. There is no one canonical formulation of the precautionary principle. Instead there are several different formulations, all of which raise significant conceptual difficulties (Clarke, 2009). The core idea behind the principle is something like 'when in doubt don't', or 'better safe than sorry' (Sandin, 2007, p. 100). The precautionary principle does not seem to add much, if anything, to the idea of risk aversion, so not much will be lost here by ignoring it.

${ }^{11} \mathrm{~A}$ complicating factor here is that a significant minority of the people who identify as conservatives and live in American Red States are libertarians, and so not conservative in the sense that is relevant to my argument. $11 \%$ of Americans describe themselves as libertarian (and understand what the term means) (Kiley 2014). This complication does not change the fact that the pattern of distribution of wealth in America favour liberals and disadvantages conservatives. 
${ }^{12}$ See http://www.politifact.com/truth-o-meter/statements/2014/jul/29/facebook-posts/are-97nations-100-poorest-counties-red-states/(accessed 16 September 2016).

${ }^{13}$ For discussion of the influence of Adorno et al. (1951), see Martin (2001).

${ }^{14}$ Jost et al. (2007) go close to suggesting that there is evidence that conservatives are risk averse. They argue that there is evidence that conservatives have a heightened need to manage uncertainty and threat. The presence of this alleged need might be thought to imply that conservatives are riskaverse. However, a need to manage uncertainty and threat could sometimes lead to risk-seeking rather than risk-averse behaviour. This might well be the case if potential threats can be headed off by accepting rather than avoiding risks, or if imminent threats can be more effectively managed by taking risks than by avoiding them.

${ }^{15}$ There are also various other less significant contributors to status quo bias. For a recent summary, see Eidelman and Crandall (2012).

${ }^{16}$ There may well be costs involved in switching between options. If so, then these can provide me with a reason to prefer to avoid switching. Thanks to an anonymous referee for this point.

${ }^{17}$ As of 19 September 2016, Kahneman and Tversky (1979), the paper in which the core ideas of prospect theory were first set out, had been cited 42146 times (Google Scholar). According to Levy 'the behavioural alternative to expected utility that has received by far the most attention in political science is prospect theory' $(2003$, p. 215). Prospect theory has been hugely successful but it has some limitations. It appears to be unable to account for the apparent roles that feelings of disappointment and regret play in shaping our responses to risk (Kahneman 2011, pp. 286-8).

${ }^{18}$ The three central claims presented here are shortened versions of Kahneman's three central principles of prospect theory (2011, p. 282). 
${ }^{19}$ What exactly is a reference point? According to Kahneman (2011) it is 'the earlier state relative to which gains and losses are evaluated' (2011, p. 281). Van Osch et al., describe a reference point as a 'point of view' (2006, p. 338). Köszegi and Rabin offer a definition of reference points tailored to business: 'a person's reference point is her probabilistic beliefs about the relevant consumption outcome held between the time she first focused on the decision determining the outcome and shortly before consumption occurs' (2006, p. 1141).

${ }^{20}$ See also Figure 10 , Kahneman (2011, p. 283).

${ }^{21}$ For further discussion of prospect theory's ability to account for evidence of the endowment effect, see Kahneman (2011, pp. 292-7).

${ }^{22}$ Also social norms, social comparisons and recent losses (Levy 2003, p. 218).

${ }^{23}$ Relatedly, they are motivated to work harder to meet goals than to exceed goals (Heath et al. 1999, pp. 83-6).

${ }^{24} 65$ research subjects were asked to choose under the 'do your best' condition' and 66 subjects were asked to choose under the 'save $\$ 250,000$ ' condition (Heath et al. 1999, p. 94).

${ }^{25}$ Pope and Schweitzer suggest that par may not always be the only reference point for professional golfers. On an easy par-five hole, expert golfers may come to treat a score of four as their reference point (2011, p. 149). Also, late in a tournament, the scores of competitors may become reference points $(2011$, p. 130).

${ }^{26}$ Interestingly, some professional golfers, such as Tiger Woods, are aware that their behaviour when putting for birdie is different from their behaviour when putting for par (Pope and Schweitzer 2011, pp. 144-5). 